\title{
Colonic Stenosis, CTCAE
}

National Cancer Institute

\section{Source}

National Cancer Institute. Colonic Stenosis, CT CAE. NCI Thesaurus. Code C143377.

A disorder characterized by a narrowing of the lumen of the colon. 